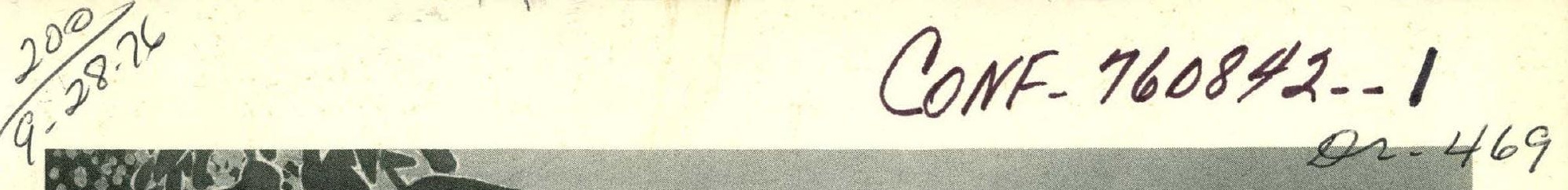

9

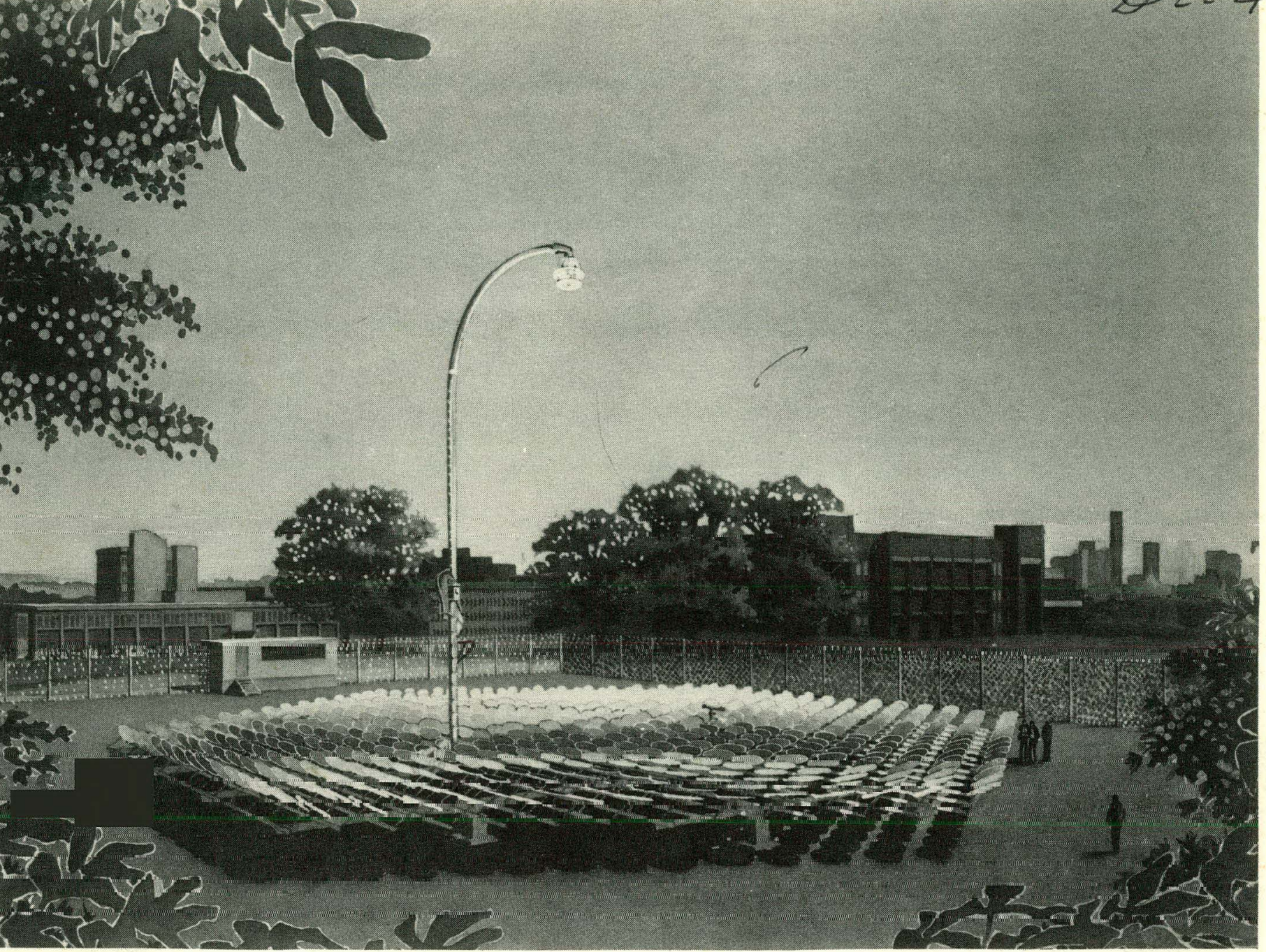

\title{
Georgia Tech 400 KWth Solar Thermal Test Facility
}

J. D. Walton, Jr., S. H. Bomar, Jr.

N. E. Poulos

AUGUST 15, 1976

Engineering Experiment Station 


\section{DISCLAIMER}

This report was prepared as an account of work sponsored by an agency of the United States Government. Neither the United States Government nor any agency Thereof, nor any of their employees, makes any warranty, express or implied, or assumes any legal liability or responsibility for the accuracy, completeness, or usefulness of any information, apparatus, product, or process disclosed, or represents that its use would not infringe privately owned rights. Reference herein to any specific commercial product, process, or service by trade name, trademark, manufacturer, or otherwise does not necessarily constitute or imply its endorsement, recommendation, or favoring by the United States Government or any agency thereof. The views and opinions of authors expressed herein do not necessarily state or reflect those of the United States Government or any agency thereof. 


\section{DISCLAIMER}

Portions of this document may be illegible in electronic image products. Images are produced from the best available original document. 


\author{
GEORGIA TECH $400 \mathrm{KWTh}^{\star}$ SOLAR \\ THERMAL TEST FACILITY \\ J. D. Walton, Jr., S. H. Bomar, Jr. and \\ N. E. Poulos \\ Engineering Experiment Station \\ Georgia Institute of Technology \\ At lanta, Georgia 30332
}

\begin{abstract}
Under ERDA Contract No. E-(40-1)-5018 Georgia Tech is constructing a $400 \mathrm{KWth}$ solar test facility for high temperature solar energy research and development. Designed by Professor G. Francia, it is an enlarged version of a central receiver facility which he developed near Genoa, Italy. The Georgia Tech facility utilizes 550 round mirrors, 111 centimeters in diameter which may be operated flat or focused to provide radiant heat fluxes from 25 to $200 \mathrm{~W} / \mathrm{cm}^{2}$ to a test area centrally located above the mirror field. Scheduled to be completed in January 1977, it will be used first to heat a boiler-superheater to deliver $365 \mathrm{~kg} / \mathrm{hr}$ of steam at 150 atmospheres and $600^{\circ} \mathrm{C}$. Other uses include evaluation of experimental receivers utilizing such heat transfer fluids as steam, air, helium, oil, molten salts and liquid metals, and basic research in the areas of metals, ceramics and coatings.

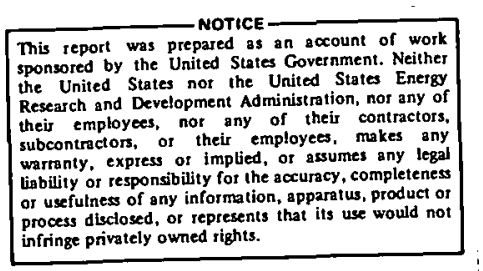

* Total radiant thermal energy concentrated at the focal plane of the
test facility is calculated to be $345-410 \mathrm{KWth}$ with incident direct solar
radiation values of $800-950 \mathrm{~W} / \mathrm{m}^{2}$.
Paper presented at the Joint Conference of the American Section of
the International Solar Energy Society and the Solar Energy Society of
Canada, Inc., August $15-20$, 1976, Winnipeg, Manitoba, Canada.
. 


\section{INTRODUCTION}

The past two years have witnessed a rapid growth of research and development efforts to develop solar thermal conversion systems for electric power generation. The solar thermal conversion system which is presently receiving the most attention is the central receiver or tall tower concept. A typical system consists of a central heat receiver, located on top of a tower, which is heated by solar energy reflected from a large number of mirrors (heliostats) which track the sun during the day.

In most present designs the central receiver is a steam generator consisting of preheater, boiler and superheater. The receiver is the interface between the incoming radiant thermal energy and the working fluid of the power cycle, and performs the same function as the fuel fired boiler in a conventional power plant. Since steam driven turbogenerators have been used for many years in the production of electricity, the major components of a central receiver solar power plant which require the development of new technology are the central receiver and the heliostats. The test and evaluation of central receivers requires the use of large scale solar thermal test facilities which presently do not exist in the United States. To remedy this situation ERDA has recently contracted for the design of a 5 MWth Solar Thermal Test Facility to be built at Sandia Laboratories, Albuquerque, New Mexico. This facility is scheduled to be operating at 1 MWth by April 1977, and at 5 MWth by late 1977 or early 1978. The only other large solar thermal test facility is the CNRS $1000 \mathrm{~kW}$ Solar Furnace at Odeillo, France. ERDA is currently funding contracts with Martin Marietta/Denver Division and Georgia Tech for the test and evaluation of the Martin Marietta 1 MWth boiler in the French facility. However, the size and complexity of experiments to test central receivers of the 1-5 MWth level suggest that there is a need for intermediate size test facilities $\left(\frac{1}{4}-\frac{1}{2}\right.$ MWth) to share the test load of the larger facilities and to expedite the development and evaluation of more advanced or novel receiver designs. Such facilities also could be used to gain experience in the study and operation of central receiver type solar thermal conversion systems. In order to accomplish these goals ERDA has funded a program at Georgia Tech 
to construct and operate a 400 KWth Solar Test Facility. This facility will be used initially to power a $350 \mathrm{kWth}$ steam generating plant and to provide the solar thermal environment necessary to evaluate various types of experimental receivers and to conduct high temperature solar thermal research.

\section{BACKGROUND}

Since about 1960, Professor G. Francia, University of Genoa, Italy, has pioneered in the design, development and construction of solar thermal systems for generating high quality steam 1,2,3,4/. Although his work has dealt with receivers much smaller than those envisioned for commercial central receiver power systems, his technical approach is remarkably similar to the concepts currently being considered in the United States. Therefore, the decision was made to import the existing know-how and experience of Professor Francia in order to obtain a relatively large solar thermal test facility in the shortest possible time. Since personnel at Georgia Tech developed the concept of this program and since they have conducted numerous solar energy programs at the CNRS $1000 \mathrm{~kW}$ Solar Furnace during the past five years, the decision was made to locate the $400 \mathrm{KWth}$ Solar Thermal Test Facility at Georgia Tech.

\section{CHARACTERISTICS OF THE GEORGIA TECH SOLAR THERMAL TEST FACILITY}

The principle of operation of the Georgia Tech Solar Thermal Test Facility (GT/STTF) is essentially the same as that of the $135 \mathrm{KWth}$ solar facility built by Professor Francia at St. Ilario near Genoa, Italy, and shown in Figure 1 . This facility utilizes 271 flat mirrors to direct the sun's rays into the boiler-superheater shown at the top center of the photograph. Each mirror, 78 centimeters in diameter is supported on a mechanical drive mount called a "kinematic motion." All of the kinematic motions are mechanically linked together through a common drive shaft so that they move together by a central clock drive mechanism to follow the sun's movement. Figure 2 shows the arrangement for mounting the kinematic motions and the drive system. 


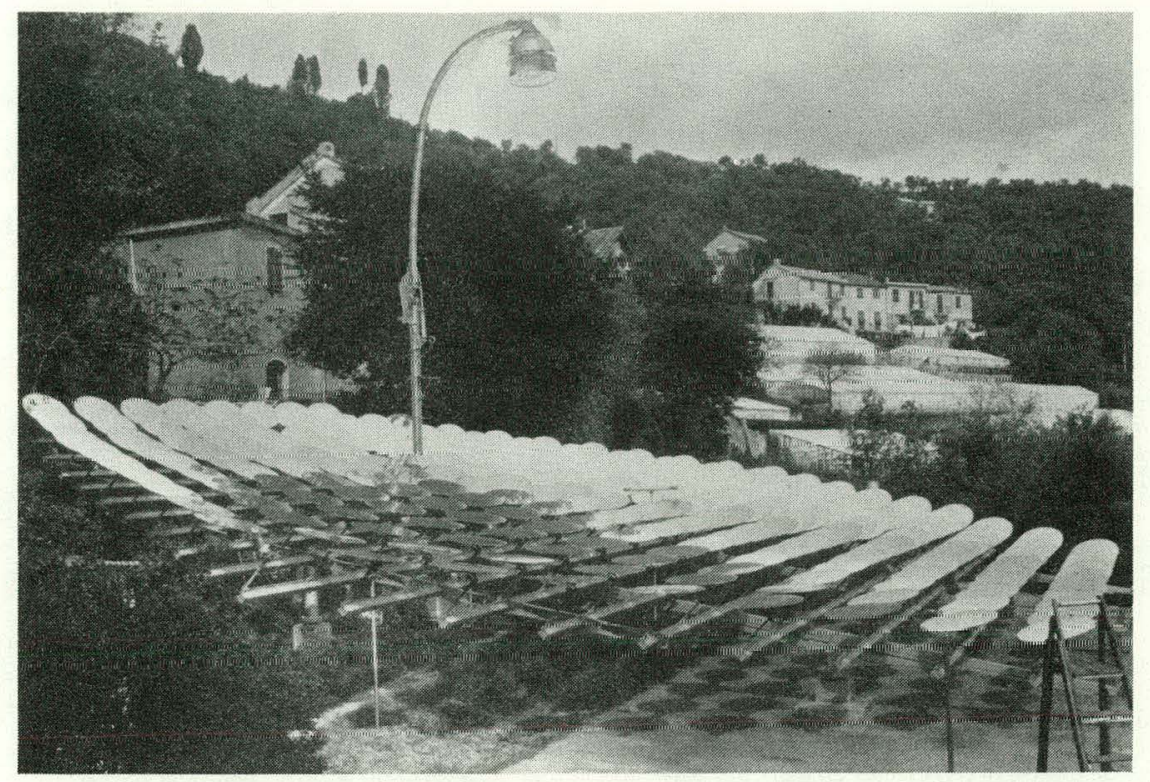

Figure 1. 135 KWth Solar Power Plant at St. Ilario near Genoa, Italy.

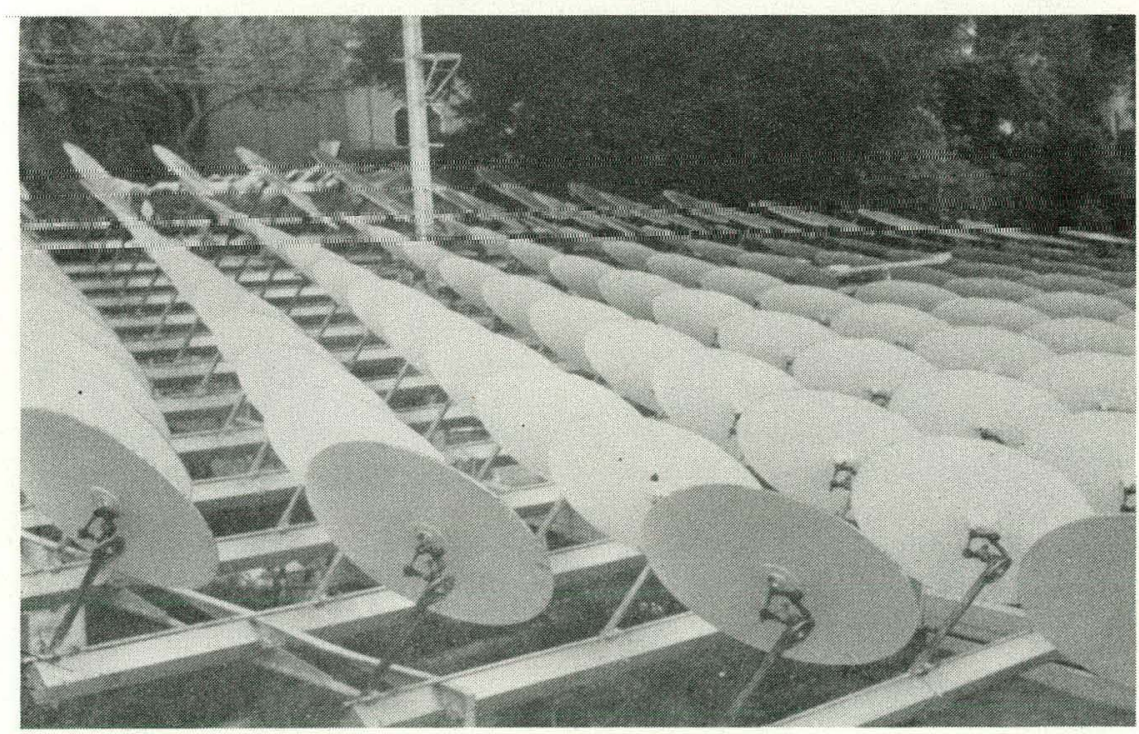

Figure 2. Arrangement for Mounting Kinematic Motions for 135 KWth Solar Power Plant. 


\section{A. Kinematic Motion Operation}

Figure 3 (a) shows the prinicple of operation of the "kinematic motions." Point $A$ is used as a reference point. Line $A B$ is the extension of a line drawn from the sun through point $A$. Line $C A$ is the extension of a line drawn from the receiver through point $A$. Lines $C A$ and $A B$ are of equal length and form the equal sides of the equilateral triangle $A C B$. The line $C M$ is an extension of the side of the triangle ACB. A mirror is placed at point $M$ perpendicular to line MCB. Since line MCB is pardllel to the bisector of angle SAR, the mirror surface will reflect the light from the sun (point $S$ ) onto the receiver (point $R$ ). To maintain this relationship as the sun moves through the day, point $B$ must rotate about axis TA, (parallel to the earth's axis) at $15 \%$ hr and MCB must rotate around point c. This figure is oriented so that axis TA is parallel to the earth's axis when located at the latitude of Atlanta $\left(33^{\circ}-47^{\prime}\right)$. Figure 3 (b) is a drawing of the kinematic motion and support arm for the Georgia Tech test facility. As illustrated in this figure the support arm will be mounted at an angle of $56^{\circ} 13^{\prime}$ from the horizontal facing south. The axis of rotation is shown by line AT which is located parallel to the earth's axis. Rotation is provided by a cable $W$ around the pulley at $P$ and driven through the shaft $S$. Alignment with the sun (line $A B$ ) is provided by a worm gear at $D$ acting on the circumferential gear arm $E$. Declination adjustments also are provided through $D$. Alignment of the receiver (line $A C$ ) is provided through point $H$ attached to a movable collar on the fixed rod $G$.

\section{B. Thermal Characteristics}

Initially, the GT/STTF will utilize 550 circular, back silvered mirrors, $111 \mathrm{~cm}$ in diameter and $3 \mathrm{~mm}$ thick, and it will be possible to utilize the mirrors either flat or focused. It is presently planned that the mirrors will be produced from low iron window glass. Although the quality of the reflected image provided by the low iron glass will not be as good as that provided by float glass, the reflectivity has been reported to be between 0.90 and 0.91 for the low iron glass as compared with 0.83 for float glass which is not available in low iron compositions. 

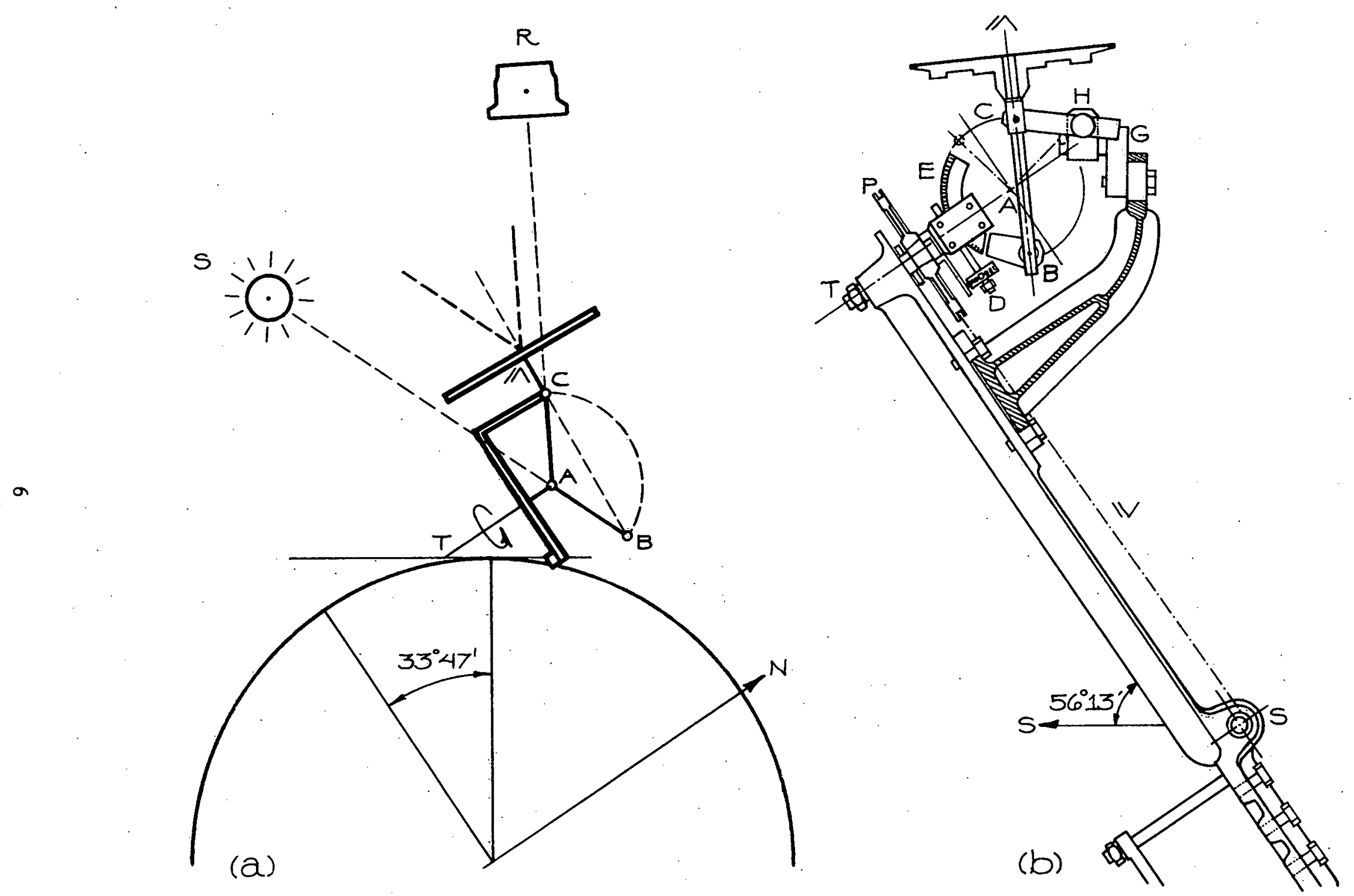

Figure 3. Schematic and Drawing of Kinematic Motion for Georgia Tech Solar Thermal Test Facility. 
The structure for supporting the kinematic motions will be rectangular in shape, 38 meters east and west and 40 meters north and south. This structure will be capable of supporting a total of 682 kinematic motions (mirrors). The initial 550 mirrors will be arranged in a hexagonal pattern with the receiver located 20 meters above the center of the field. The kinematic motions will be capable of directing the concentrated solar energy onto a "north-facing" receiver, located above the south edge of the field as well as a downward facing cavity above the center of the field.

The actual total thermal energy which can be provided by this facility will depend upon the number of mirrors, the incident direct solar radiation and the time of year and time of day. In order to give an idea of the thermal power which will be available with this facility using 550 mirrors, Figure 4 was prepared. This figure shows the thermal balance for noon of equinox for direct solar radiation values of 800 and $950 \mathrm{~W} / \mathrm{m}^{2}$. The range of values for the radiant thermal energy available at the focal plane or aperture of the receiver is 345 to $410 \mathrm{kWth}$. If this facility is used to power a steam boiler-superheater with a radiant thermal energy conversion efficiency of 0.95 , it should be possible to produce superheated steam at a thermal power level of between 328 and $390 \mathrm{kWth}$. Under these conditions the net thermal efficiency of the total system will be about 77 percent.

\section{Steam Power Generation}

A steam boiler-superheater also will be available for operation with the GT/STTF. The configuration will be similar to the one shown in Figure 1 and the thermal efficiency has been calculated to be 0.95 . This boiler-superheater is rated at $350 \mathrm{KWth}$ and is designed to deliver $365 \mathrm{~kg}$ of steam per hour at 150 atmospheres and $600^{\circ} \mathrm{C}$.

This boiler-superheater will be incorporated into the thermal cycle shown in Figure 5 . The basic operation of this cycle is the same as for the $100 \mathrm{KWth}$ steam system developed at St. Ilario. The condenser will be capable of handling the total thermal output of the boiler-superheater in order to study the performance for the receiver while conserving the feedwater and without the necessity of operating some type of machinery. For demonstration purposes a steam turbine can be incorporated into the thermal 


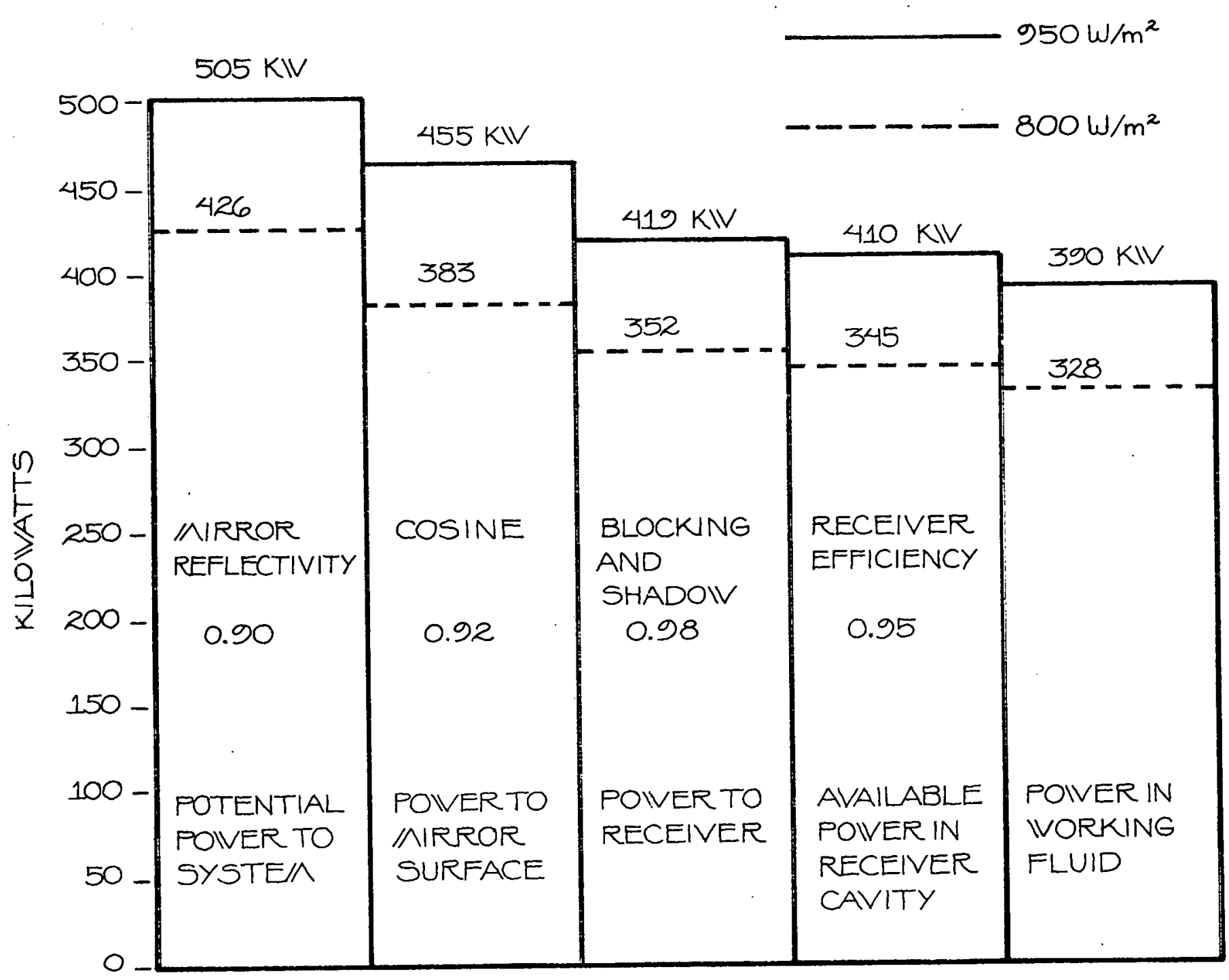

Figure 4. Thermal Balance for Noon of Equinox for Direct Solar Radiation of $800 \mathrm{w} / \mathrm{q}^{2}$ and $950 \mathrm{w} / \mathrm{m}^{2}$. 


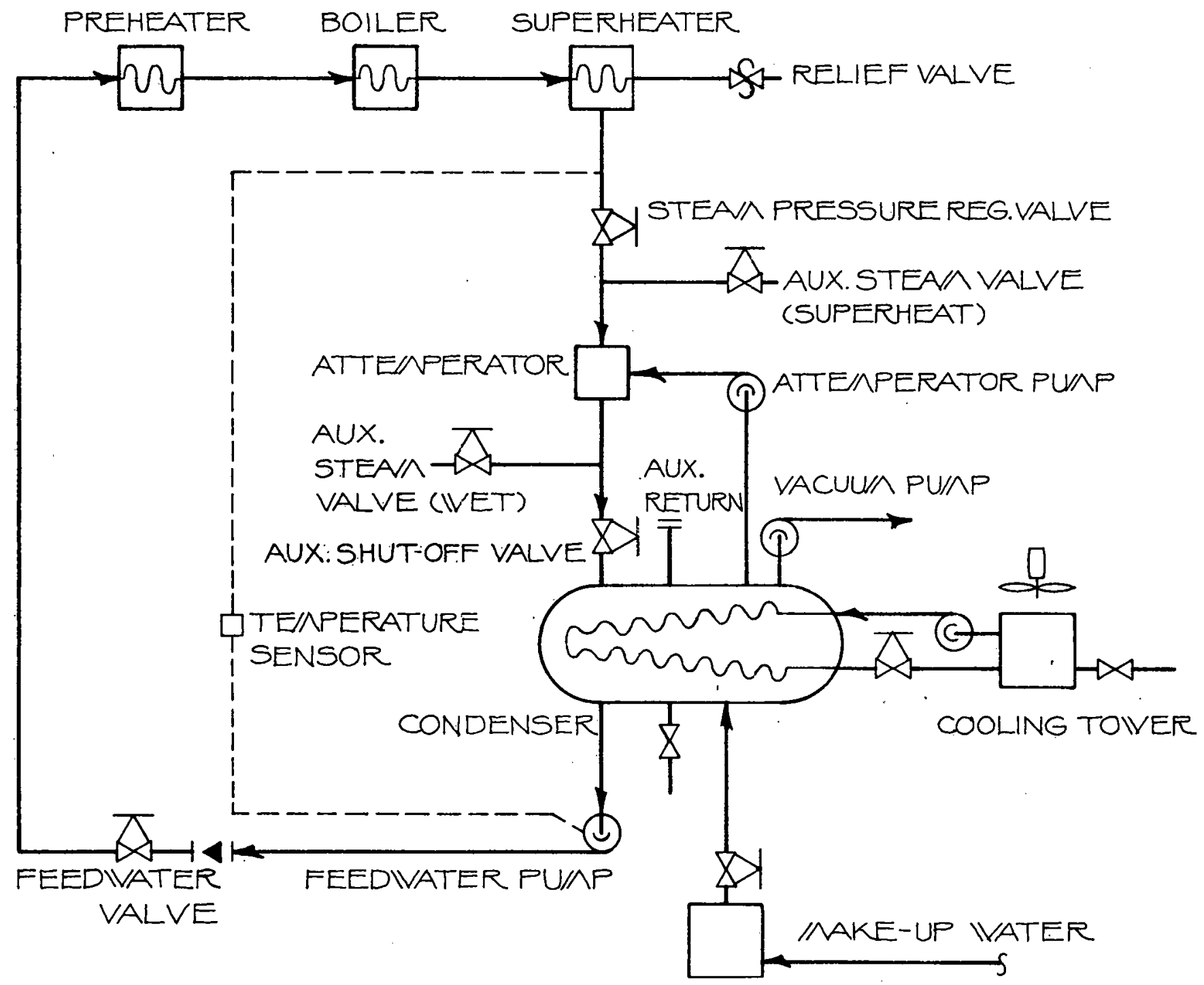

Figure 5. Preliminary Thermal Cycle Diagram. 
cycle. Also, the steam attemperator can be used to desuperheat the steam in order to power a steam engine or other device which requires lower quality steam.

\section{Thermal Test Capabilities and Areas of Application}

In order to estimate the range of radiant thermal fluxes which might be provided by the GT/STTF, the data shown in Figure 6 were calculated. The conditions assumed were for 550 mirrors, 111 centimeters diameter with an incident direct solar radiation value of $800 \mathrm{~W} / \mathrm{m}^{2}$. The concentrated radiant thermal energy is assumed to be at the focal plane located 20 meters above the center of the mirror field. The data for the focused mirrors are based on optimum focusing on the focal plane. The maximum heat flux and concentration ratio values assume a test area in which at least 50 percent of the total radiant thermal energy (175 KWth) is available. The minimum values are for an area into which all of the thermal energy (350 KWth) is available. For the focused mirrors the distribution of concentrated thermal energy is based on the solar image size at a distance of 24 meters and assumes a distribution of heat flux values similar to that obtained by Trombe, et al., for the CNRS $1000 \mathrm{~kW}$ Solar Furnace 5/. The temperatureheat flux relationship shown in Figure 6 was obtained from data presented by Trombe $6 /$. These temperatures are the equilibrium black-body temperatures associated with the corresponding radiant heat flux.

The range of values for temperature, heat flux and concentration ratio can be extended below those shown in Figure 6 by using fewer mirrors or by utilizing a test area which is removed from the focal plane. Within limits the heat flux values can be extended above those shown by reducing the size of the test irea and accepting a lower total test power level. It should be emphasized that these are calculated values and that the actual thermal capabilities of this facility will not be available until after the construction is completed and thermal measurements have been made. However, from these calculations it appears that this facility should be capable of providing the range of radiant thermal energy values needed to conduct a wide variety of high temperature solar-thermal experiments. Therefore, it should be possible to realistically evaluate numerous receiver concepts with 
CONCENTRATION RATIO

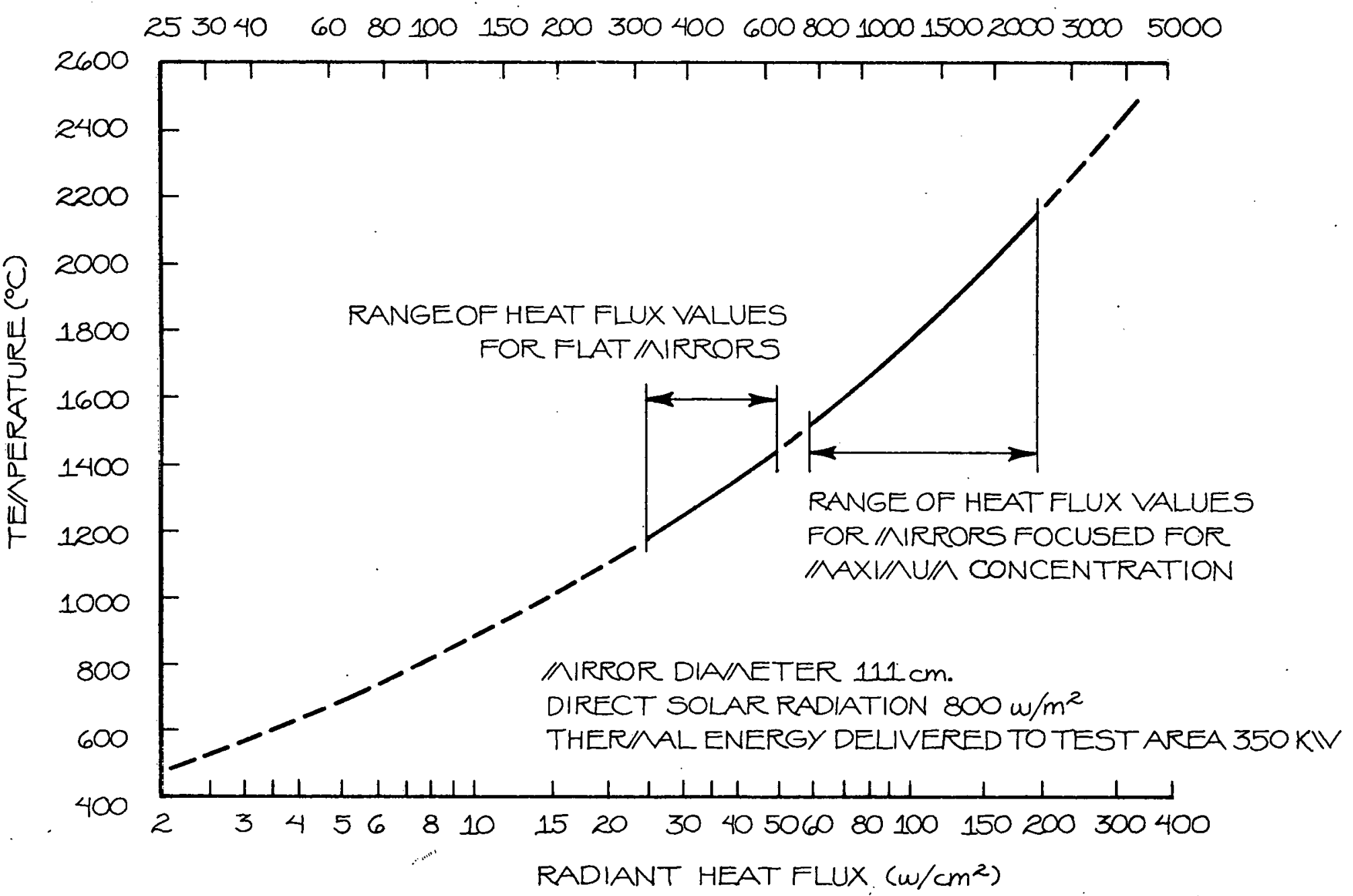

Figure 6. Estimated Thermal Capabilities of the Georgia Tech Solar Thermal Test Facility. 
respect to thermal-optical-geometric performance. Examples of receivers which could be evaluated in this facility include steam boiler-superheaters, and gas, (air, helium), oil, molten salt and liquid metal cooled heat exchangers. This facility also is suited for carrying out high temperature thermochemical reactions, the evaluation of thermionic devices and for more basic research in the areas of metallurgy, ceramics and coatings.

The overall system is ideally suited for incorporation into total energy system studies as well as high temperature thermal storage experiments. When operating as a solar steam power plant the Georgia Tech facility offers a unique system for obtaining on-hand operation experience, and thus should aid in identifying and solving problems which might be encountered in the future operation of a large scale solar power plant.

Figure 7 is a schematic representation of a possible configuration for incorporating an electric power/total energy system, a thermal storage systeil and a thermal loop for liquid cooled heat exchangers into the GT/STTF.

\section{CONSTRUCTION SCHEDULE}

The GT/STTF is being constructed on the main campus of the Georgia Institute of Technology in Atlanta, Georgia. Construction is scheduled to be completed in December 1976, with limited operation expected during January 1977. Calibration and check-out will be conducted during the first half of 1977, and the facility should be available for the conduct of solar thermal tests by July 1977.

An artist rendering of the facility as it will appear at Georgia Tech is shown in Figure 8. A preliminary plan of the test site including the solar facility and auxiliary units is shown in Figure 9.

\section{PLANS FOR OPERATION}

A document describing the GT/STTF is being prepared. This document will describe the design and operation of the facility and will include a list of available equipment, instrumentation and other support equipment. Also included will be a description of various types of experiments which might be conducted. Table I summarizes some of the potential applications for the GT/STTF. 


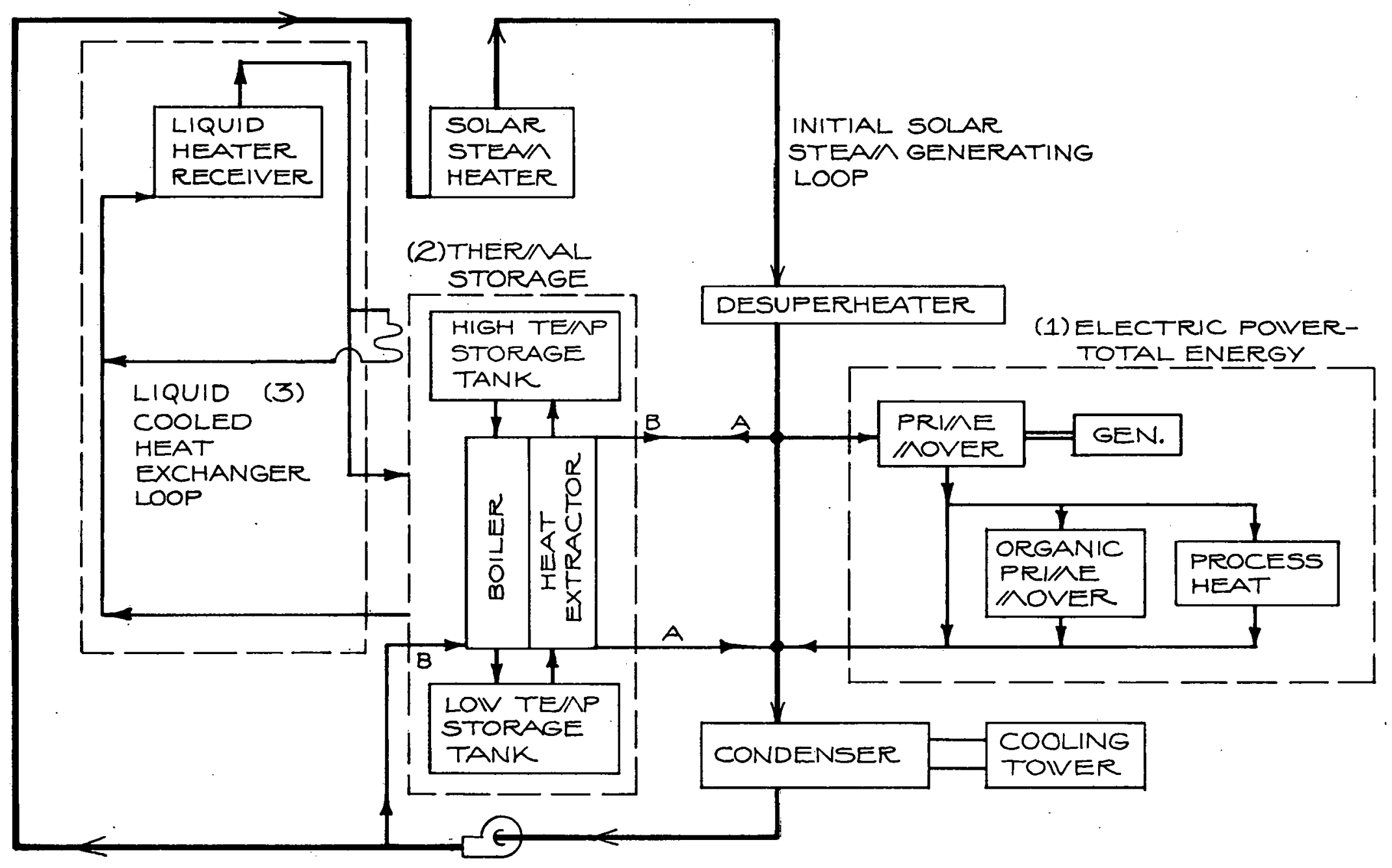

Figure 7. Schematic of Possible Configuration for Incorporating (1) Electric Power-Total Energy, (2) Thermal Storage, and (3) Liquid Cooled Heat Exchanger into Georgia Tech Solar Thermal Test Facility. 


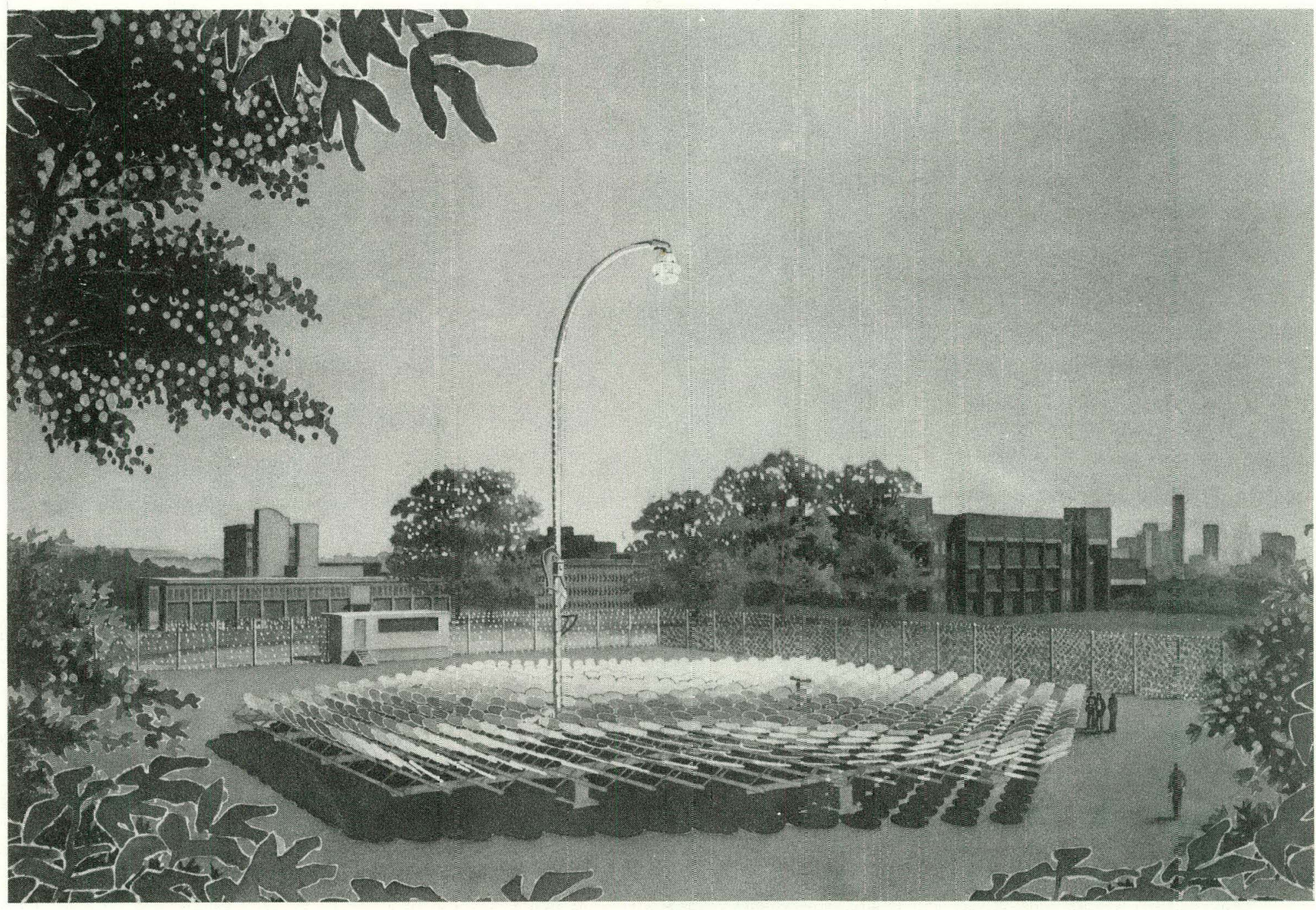

Figure 8. Artist Rendering of the Georgia Tech Solar Thermal Test Facility. 

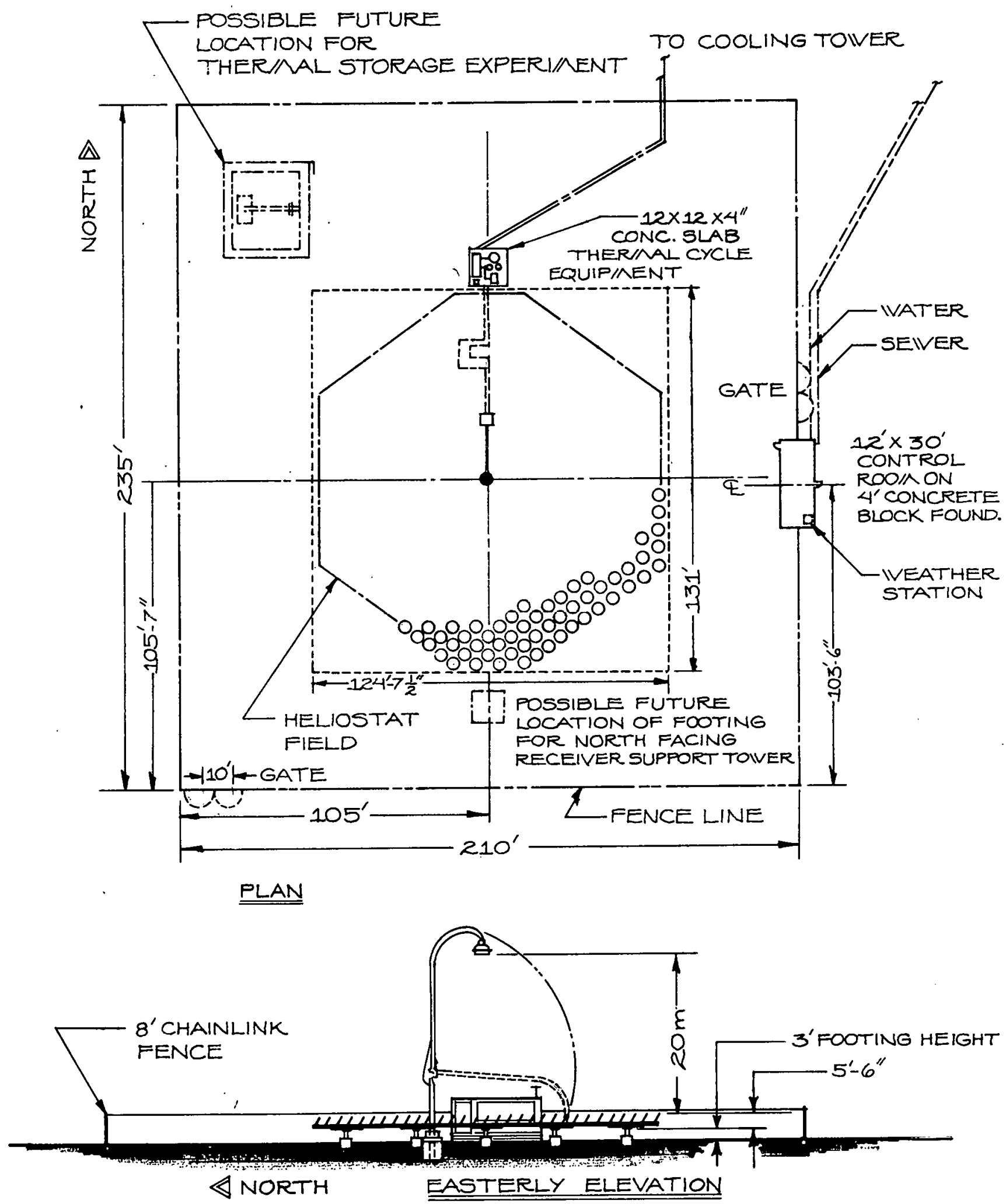

Figure 9. Preliminary Site Plan for the Georgia Tech Solar Thermal Test Facility. 
TABLE I

APPLICATIONS FOR THE GEORGIA TECH

SOLAR THERMAL TEST FACILITY

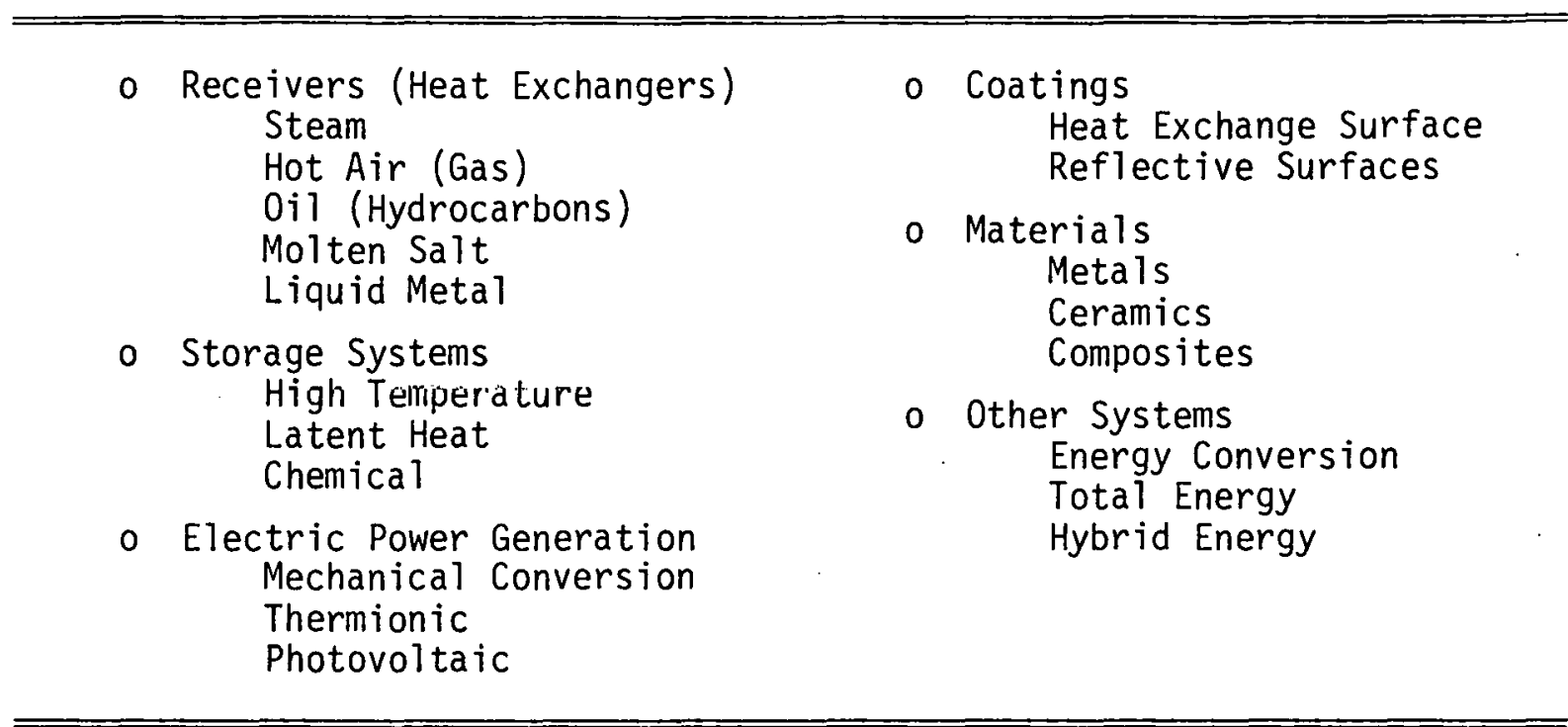

One section of this document will serve to inform potential users on procedures to be followed in order to have experiments conducted at the facility. In this section the user will be advised how to describe the test to be conducted including test conditions and data to be provided. Also, the user will be required to prepare a written assessment of the hazards of the experiments to be conducted. Approval of the experiment in the facility will be contingent on acceptance of the hazards assessment by a safety panel.

ERDA views the GT/STTF as an important research, development, test and evaluation tool available to all ERDA contractors as well as other persons and organizations conducting solar thermal related work requiring such a facility. Potential users are encouraged to advise Georgia Tech of their interest. Suggestions concerning other areas of application for this facility are also encouraged. Correspondence should be addressed to:

J. D. Walton, Jr., Technical Manager

Solar Energy Programs

Engineering Experiment Station

Georgia Institute of Technology

Atlanta, Georgia 30332 


\section{REFERENCES}

1. G. Francia, "Pilot Plants of Solar Steam Generating Stations," Solar Energy, 12, no. 1, p. 51-64 (September 1968).

2. G. Francia, "The University of Genoa Solar Furnace," Presented at the NSF International Seminar on Large Scale Solar Energy Test Facilities, New Mexico State University, Las Cruces, November 1820, 1974 .

3. G. Francia, "The Solar Plant of S. Ilario-Genova Nervi," La Ricerca Scientifica, 36, no. 8, p. 779-784 (August 1966).

4. G. Francia, "A New Collector for Solar Radiant Energy: Theory and Experimental Verification," Proceedings of the United Nations Conference on New Sources of Energy, Rome, Italy (1961).

5. F. Trombe, L. Gion, C. Royere and J. F. Robert, "First Results Obtained with the 1000 kH Solar. Furnace," Solar Energy, 15, pp. 63-66 (1973).

6. F. Trombe and A. Le Phat Vinh, "Methodes de Concentration de l'energie Solaire," Cahiers de l'A.F.E.D.E.S., no. 3, p. 104 (November 1971). 